\title{
THE USE OF COMMISSIVE SPEECH ACTS IN ENGLISH AND BULGARIAN AND THEIR POLITENESS IMPLICATION
}

\author{
Deyana Peneva*
}

\begin{abstract}
The paper focuses on one specific performative speech act and in particular on examining the grammatical, propositional and pragmatic meaning of a basic illocutionary act which belongs to the group of commissives in comparison with its Bulgarian equivalents and namely the verb agree. The article also presents a quantitative and qualitative analysis of a database taken from the Bulgarian media discourse and $B N C$ /British National Corpus/ of spoken language which is also needed to identify the tendency in the use of commissive speech acts cross-culturally which can be useful to make further interpretation especially with respect to politeness implications.
\end{abstract}

Key words: commissive speech acts, proposition, pragmatic meaning, politeness, semantic content

\section{Introduction}

The article aims to explore the speech acts phenomena cross-culturally specifying the discrepancies, either minor or marked, with respect to their grammatical form, propositional content and pragmatic. Though a number of studies have been conducted comparing and contrasting the speech act utterances among different languages, a limited number of surveys have dwelt on the cross-cultural issue of speech act disparities between English and Bulgarian commissive illocutionary acts. It is believed that a more detailed analysis will be essential for advanced students in English so that they can grasp important peculiarities in communicative styles in both cultures - native and non-native. The study is made to designate not only the grammatical and propositional contrasts, but make explicit the politeness aspects in both cultures pragmatically. In that respect, the present paper focuses on a particular commissive speech act, expressed directly by a performative verb and namely, the verb agree and its respective equivalents in Bulgarian.

\footnotetext{
* Assist. Professor PhD at Shumen University, Department of English Studies, Shumen, Bulgaria, e-mail: d.peneva@shu.bg.
} 


\section{Previous research in the field}

In recent years the number of articles regarding the problem of intercultural speech act analysis has piled up dramatically focusing on the different groups of communicative acts which are divided into five basic sections according to their illocutionary force and real-life implications (Austin 1962; Strawson 1964; Searle 1969; Hymes 1972):

1) assertives or representatives: statements that are performed by the speaker and may be taken as true or false because they describe a state of affairs in the world; the speaker becomes responsible for the truth of the propositional content (asserting, concluding): It's snowing.

2) directives: the speaker tries to make the hearer act in a way which will fit the propositional content, for example, forbidding: Don't write on the desk.

3) commissives: statements which commit the speaker to a set of actions represented by the propositional content, for example, agreeing, inviting, promising; assuming of an obligation or declaring of an intention: I promise I won't do that again./ I agree with the fact that Lilly is constantly absent.

4) expressives: these are statements which express a psychological state or "sincerity condition of the speech act": thanking, apologizing. For example: $I$ apologize for my rude behaviour.

5) declaratives: statements that ask for an immediate change in the institutional state of affairs and attempt to change the world (the extralinguistic institution) by "representing it as having been changed" (Searle 1969) (as in declaring war, christening, wedding ceremonies: Priest: I now pronounce you husband and wife).

However, there is a narrow set of pragmatic surveys on comparing communicative acts in English and Bulgarian focusing on compliments examination (Vlahova 2000; Dimitrova 2009; Ivanova 2012), apologies (Peneva 2015) and on requests (Hristov 2008) Commissive speech acts have not been explored in a comparative study regarding Bulgarian and English languages, nor has the verb agree been analysed cross-culturally with respect to its grammatical frame, semantic meaning and usage.

\section{Research Questions}

The paper makes an attempt to collect, classify and analyze the data taken from $\mathrm{BNC}$ of spoken language (British National Corpus) in which the performative agree appears in first person singular, Present Simple tense and data extracted from three Bulgarian TV programmes, talk shows and debate format radio programmes where the Bulgarian performative equivalent is represented by a different part of speech. In that respect all equivalents in Bulgarian in first 
person singular, Present tense from video and audio sources were taken out, transcribed and divided into groups. The paper aims to answer the following questions:

1) What are the preferred agree patterns performed by Bulgarian learners?

2) To what extent do the grammatical structures used by Bulgarian learners of English deviate from those of the native speakers of English?

3) How do Bulgarian learners differ from English native speakers in their pragmatic communicative behaviour as determined by expressing agreement regarding different contextual factors?

4) What type of politeness orientation (positive or negative) (cf. Bach 2004) is favoured in both languages?

\section{Methods}

The article aims to classify the linguistic features which are identified in both corpora following the syntactic patterns of the performative entries in English and Bulgarian.

With regard to the identification and classification of linguistic material in patterns one basic method of analysis is used for both corpora: Quantitative and qualitative corpus analysis (following Biber, Conrad, Reppen 1998) which is based on Valency patternbank model (following Herbst et al 2004; Herbst, Schüller 2008) for the analysis of syntactic patterns and the speech acts data elicitation with respect to pattern preference and politeness orientation. The linguistic material provides a tool for linguistic research in the areas of valency, complementation, semantic roles and construction grammar (Herbst et al 2004: 6). It is of great use in that it could provide the scholar with the main frameworks when identifying the verbs, adjectives and nouns concerning all valency patterns that become explicit. Furthermore, it will also help in identifying and analyzing the syntactic deviations and consequently will give material in specifying the differences and preferences in the use of agree commissive utterances crossculturally.

The coding of the valency patterns comprises a large set of symbolic devices and a very large number of abbreviations.

The range of symbolic devices and abbreviations chosen for the purposes of the present paper includes:

$\mathbf{C L}$ - clause; Vp - verb phrase; $\mathbf{N p}$ - noun phrase; V-ing - gerundial clause

qualitative valency, that is, in the margins of the examples a letter $(\mathbf{Z}, \mathbf{M}, \mathbf{D}$, $\mathbf{T})$ is written specifying the number of complements accompanying a given performative ( $\mathrm{Z}$ - for zero, $\mathrm{M}$-one, $\mathrm{D}$ - two, $\mathrm{T}$ - three); 
each separate valency pattern will be indicated with the letter P (P1, P2 ...)

\section{Data Analysis}

The analysis is made on the basis of three criteria: syntactic (grammatical), lexical-semantic (propositional) and pragmatic, that is - form and function, meaning and usage respectively.

The verb AGREE in English language

Agree is a content word as it is part of the basic Structural units and as such it possesses a semantic meaning. It falls into the group of verbs and is one of the main constituents of a clause and namely the Verb (Downing, Locke 2006). In that respect it could either be regarded as transitive or intransitive.

Agree becomes explicit in nine basic syntactic patterns of construction (Oxford Dictionary)

P1 (Z) agree + [no object] /intransitive/

ex. They say that a change is needed and I agree completely.

$\mathbf{P 2}(\mathrm{M})$ agree $+\left[\mathbf{w i t h}+\mathbf{N} \mathbf{p}_{\text {someone }}\right]$ /transitive/

ex. I agree with her.

$\mathbf{P 3}$ (M) agree $+\left[\right.$ with $\left.+\mathbf{N} \mathbf{p}_{\text {something }}\right] \quad$ /transitive/

ex. I I agree with your opinion.

$\mathbf{P 4}(\mathrm{M})$ agree + [about/on $\left.+\mathbf{N} \mathbf{p}_{\text {something }}\right] \quad$ /transitive/

ex. I I agree on the date of the examination.

$\mathbf{P 5}$ (D) agree $+\left[\mathbf{w i t h}+\mathbf{N} \mathbf{p}_{\text {someone }}\right]+\left[\right.$ about/on $\left.+\mathbf{N} \mathbf{p}_{\text {something }}\right]$ /transitive/ ex. I agree with him about the oncoming proceedings.

P6 (M) agree + [that-CL] /transitive/

ex. I agree that she made a really good impression.

$\mathbf{P 7}(\mathrm{M})$ agree $+[\mathbf{t o}+\mathbf{N p}] \quad$ /transitive/

ex. I agree to their offer.

P8 (M) agree $+[$ to + Vp] /transitive/

ex. I I agree to meet on Thursday.

P9 (M) agree + [what/where + CL] /transitive/ no examples.

In P1 the verb agree does not take any complements or valencies which makes it intransitive whereas in patterns P2-P9 the verb is followed either by one complement or two (P5) making it transitive. 
With respect to its lexical-semantic content the entry connotes either:

1. the state of having the same opinion, sharing the same opinion with someone else or

2. saying that you will do, accept, or allow something that is suggested or requested by another person.

3. deciding to accept something after discussing what should or might be done.

Since present research paper deals basically with the verb agree with respect to its commissive use, I should give a more profound overview of what exactly 'commissive' means.

According to Austin (1962) and supported by Bach (2004) there is a set of four conventions or the so called felicity conditions in speech act pragmatics that should be present in each illocutionary utterance so that it can be considered valid. They are propositional act, preparatory condition, sincerity condition and essential condition. Austin pointed out that 1) the propositional content condition focuses mainly on textual content and propositional meaning which refers extensively to semantics; 2) the preparatory condition focuses upon background circumstances and the participants in the speech act (social status, social distance, age); 3) the sincerity condition regards the psychological state of the speaker and his/her intentions, though it is often argued that it is difficult to determine whether or not the speaker is being sincere; 4) essential condition implies the idea and the intention of the speaker to agree/disagree with the other party, that is: the communicative act counts as an act of agreement, that is the change of state of the speaker.

The presence of these four conditions makes a successful speech act, which is described not as true or false based on truth-value semantics but more as felicitous. Otherwise the speech act can be viewed as false or infelicitious.

With a view of the above mentioned, commissives may be expressed by performative verbs such as promise, swear, guarantee, vow, agree. They are illocutionary speech acts that the speakers use to "commit themselves to some future action" (Yule 1996: 55), in that the speakers assume of an obligation by declaring their intention.

According to speech act theory the verb agree falls simultaneously to two groups of communicative acts, i.e. it can either belong to the group of assertive illocutionary acts or the commissive utterances, expressing different propositional meaning. These two meanings are intertwined and it is rather complicated to separate them from one another as the commisive use comes as a natural consequence of the assertive use and more specifically: 
- In assertive illocutionary sense, to agree is to assert a proposition, which refers to a (potential) fact or state of affairs about the world, which can be true or false and becomes explicit on sentence level and has to do with presupposing that another person has previously put forward that proposition. It has also more in common with preparatory condition in which to agree means to assert a proposition while presupposing that the other party has previously submitted that proposition. Since agree occurs with three basic semantic meanings, in expressing assertive communicative act of agreement the first meaning becomes explicit when sharing the same opinion. For example:

I agree with you that the plan won't work.

lassertive/

I agree to your proposal.

lassertive/

I agree entirely with what you have said.

lassertivel

When being used as a commissive performative, the verb agree comes with its second and third semantic meaning where the sincerity condition refers to the effect of being in agreement with the content of the proposition. The speaker commits him/herself to tolerating the action he/she has accepted. In general, the speaker accepts /agrees with/ the proposition by permitting the proposition to be done. In this sense it has to do with the psychological state of promising to support or assisting something and the aspect of obligation is present while it is absent in agree patterns expressing assertion. For example:

The EU preservation order should be enforced immediately. I agree completely.

/commissivel

I kindly agree to help. /commissive/

I agree on common strategy.

/commissive/

I agree on any of the proposals.

/commissive/

We agree what to do.

/commissive/

I agree to go on camera after the trial.

/commissive/

I agree with the head upon the matter of redundancies. /commissive/

The British corpus comprises 135 agree utterances in which agree is present as a single word or in constructions and occurs with both its assertive and commissive meaning in first person singular, present simple tense. The data were collected, counted and classified with regard to the frequency of occurrences of agree.

The overall number of agree utterances and their percentage rate is presented in the table: 


\begin{tabular}{|c|c|c|c|c|}
\hline \multirow[t]{2}{*}{ British reference corpus } & \multicolumn{2}{|c|}{ Number of utterances } & \multicolumn{2}{|c|}{ Per cent } \\
\hline & assertive & commissive & assertive & commissive \\
\hline P1 agree $+[$ no object $]$ & 12 & 7 & $8.9 \%$ & $5.2 \%$ \\
\hline $\mathrm{P} 2$ agree $+\left[\right.$ with $\left.+\mathrm{Np}_{\text {someone }}\right]$ & 56 & 0 & $41.5 \%$ & $0.00 \%$ \\
\hline $\begin{array}{l}\text { P3 agree }+[\text { with } \\
\left.+\mathrm{Np}_{\text {something }}\right]\end{array}$ & 16 & 4 & $11.8 \%$ & $2.9 \%$ \\
\hline $\begin{array}{l}\text { P4 agree }+ \text { [about/on }+ \\
\left.\mathrm{Np}_{\text {something }}\right]\end{array}$ & 1 & 6 & $0.7 \%$ & $4.4 \%$ \\
\hline $\begin{array}{l}\text { P5 agree }+[\text { with } \\
\left.+\mathrm{Np}_{\text {someone }}\right]+[\text { about/on/ } \\
\left.\text { upon }+\mathrm{Np}_{\text {something }}\right]\end{array}$ & 0 & 4 & $0.0 \%$ & $2.9 \%$ \\
\hline P6 agree $+[$ that-CL] & 1 & 8 & $0.7 \%$ & $5.9 \%$ \\
\hline $\mathrm{P} 7$ agree $+[$ to $+\mathrm{Np}]$ & 0 & 0 & $0.0 \%$ & $0.0 \%$ \\
\hline $\mathrm{P} 8$ agree $+[$ to $+\mathrm{Vp}]$ & 0 & 14 & $0.0 \%$ & $10.4 \%$ \\
\hline $\begin{array}{l}\text { P9 agree }+[\text { with }+ \text { what/ } \\
\text { where }+\mathrm{CL}]\end{array}$ & 6 & 0 & 4. $4 \%$ & $0.0 \%$ \\
\hline Total & 92 & 43 & $\sim 68.0 \%$ & $\sim 32.0 \%$ \\
\hline
\end{tabular}

In the Reference corpus the assertive performative agree occurs 92 times, that is approximately $68.0 \%$ of the total number of occurrences (135). In 43 cases, which is $32,0 \%$ of the total, agree is used in a commissive meaning. This is a ratio of well over 2:1 which makes the assertive agree patterns more favoured with respect to the frequency of occurrences. Consequently, the assertive illocutionary force prevails over the commissive pragmatic use.

Regarding the commissive structures in particular, it is obvious that they become explicit in 6 valency (syntactic) models offering zero, nominal, verbal and clausal complements. The corpus data analysis shows that three syntactic patterns take the leading positions with respect to their overall use: P8 agree + to $+\boldsymbol{V P}$ (in 14 out of 43 commissive utterances) followed by $\mathbf{P 6}$ agree + that$\boldsymbol{C L}$ (illustrated in 8 illocutionary acts) and P1 agree+ no complement (in 7 sentences). Valency patterns P4, P3 and P5 rank last with respective figures 6 agree + [about/on $+\boldsymbol{N} p_{\text {something }}$ I utterances while $\mathrm{P} 3$ and $\mathrm{P} 5$ syntactic structures are equal in cases (4 namely).

We can see that according to BNC of spoken language agree $+\boldsymbol{t o}+\boldsymbol{V P}$ structure is present in socially different environments which may require either a high level of formality or neutral register illustrating the social distance and status of the participants, though the utterances sound more formal than all the other commissive performative utterances. With respect to politeness, the speaker is 
willing to keep the hearer's positive face emphasizing commitment implying feelings of sympathy and interest; asserting/presupposing the knowledge of hearer's concerns. What is more, the $\mathrm{Vp}$ which follows the performative verb asks for an action on the part of the hearer which further stimulates and reasserts the hearer's commitment to take further actions not only to confirm what the hearer has already said but makes the utterance sound more genuine strengthening the illocutionary force and reinforcing the sincerity condition. This pattern is basically preferred when the intended/ implied meaning is not only to assert the validity of what one of the parties has stated, but also to show intention and express willingness to personally develop and put forward the conditions of the utterance which asks for agreement.

The syntactic pattern which ranks second with respect to frequency of occurrences agree + that-CL (P6) shows roughly the same level of formality in that the social status and distance may vary. Another point is that at times the pattern sounds ambiguous as the assertive and commissive uses may overlap unless there are additional communicative acts to illustrate that the speaker will commit further actions. For example:

I agree that legal separation should be enforced in Eastern European countries and I will take the matter personally.

The sentence comprises two clauses bearing an illocutionary force. The first one is the commissive act of agreement which is further supported by an indirect communicative act of promising which on its part further guarantees the sincerity condition. Taken separately, the act of agreement will sound vague and unsustainable if it is not supported by acts expressing commissive illocutionary force.

Taking agree+ no complement pattern next (P1), it follows a similar trend to that in pattern P6 though a complement is not explicit. The utterance is either preceded or followed by another communicative act which may express an explanation, promise, guarantee or another speech act which supports the illocutionary act bearing the performative verb agree. For example:

The PM's rejection to enforce the new immigration procedures should be taken seriously. I absolutely agree. I guarantee respective steps should be considered.

The commissive force does not become obvious unless other illocutionary acts are added bearing commissive pragmatic content. In the example the commissiveness is illustrated by the commissive act of guarantee which on its part may be regarded as a firm promise that an individual or inanimate entity will do something. Given the absence of this communicative speech act, the agree speech act cannot function as a commissive utterance and most probably will be considered as assertive expressing firm agreement rather than assuming of an 
obligation for further actions. Positive politeness aspect is also present since the speaker uses communicative utterances which definitely refer to the speaker's need to save the hearer's positive face trying not to restrict the hearer's personal freedom but rather keep his personal positive self-image/respect. Another point that we should take into account is that in P1 cases, especially when the social distance and power relationships between the speaker and the hearer are not equal, the speaker uses more than one communicative act so that the sincerity condition can be met.

Syntactic structures P4 agree + about/on $+N P$, P3 agree + with $+N p$ and P5 agree + with-NP +about/upon-NP pragmatically support the P1 analysis confirming the fact that without other strategies /speech acts/ the commissive aspect does not become evident.

\section{The Bulgarian equivalent of the English verb AGREE}

In Bulgarian language the act of agreement connoting the idea of assertion or commissiveness is expressed by the verb saglasyavam se (6 cases) and the past participle saglasen sam (51 utterances).

With respect to the verb saglasyavam se semantically it equals the verb agree in its first sentence meaning, that is, accepting the proposition that one of the parties has already introduced. The verb is intransitive and non-perfective. Additionally, it is reflexive in that it cannot be used without the particles se or $\boldsymbol{s i}$ which is an obligatory constituent of the verb head complex (the verb itself). Similarly, agree also appears as intransitive in its assertive meaning. Contrary to the Bulgarian equivalent, the English verb agree cannot be viewed as perfective or non/im-perfective since the aspect of perfectiveness is rather unstable in English language. In that respect, agree as a stative verb does not use the progressive forms, imperfective respectively. On the other hand, saglasyavam se in Bulgarian as a non/im-perfective verb describes ongoing semantic role and does not include in its interior composition the aspect of habitual or repeated semantic meaning which is present in the English verb agree. In Bulgarian corpus only 6 examples were identified in assertive illocutionary force. For example:

Saglasyavam se s Vasheto stanovishte. Prodalzhavame diskusiyata, kolegi. in En. I agree with your statement. We proceed with the discussion, colleagues./

Turning to the second way of expressing agreement in Bulgarian, namely the phrase saglasen sam, it can be used both in assertive and commissive connotation. Twenty-three cases were excerpted from the Bulgarian database bearing a commissive illocutionary force. Grammatically it can function as an adjective and also as a past participle of the reflexive verb saglasyavam se. In its commissive meaning it functions as past participle. It is a common practice 
for Bulgarian learners of English to wrongly use the grammatical structures typical to the English verb agree as Bulgarian learners transfer their native grammatical knowledge into the foreign language (Tsvetkova 2014). Instead of saying I agree, they tend to say I am agree which is a direct translation to the Bulgarian phrase Az sam saglasen. Grammatically the phrase follows a syntactic pattern given below: $\boldsymbol{N p}+\boldsymbol{V p}+\boldsymbol{A d j P}$

$\mathrm{Az}$ sam saglasen

I am agree

where the Adjectival Phrase is presented by the past participle of the verb saglasyavam se. However, this syntactic pattern is of limited use in Bulgarian language, saglasen sam prevails instead, which follows AdjP $+\mathrm{Vp}$ syntactic pattern. Actually the past participle form saglasen acts as a predicative in the syntactic pattern.

Going further into the discussion, the phrase saglasen sam follows almost the same valency patterns as the English verb agree:

P1 saglasen sam $+s-C L$

P2 saglasen sam + da-INF

P3 saglasen sam $+s-C L+d a-I N F$

P4 saglasen sam + che + CL

P5 saglasen sam + otnosno-CL
/I agree with/

/I agree to/

/I agree with ... to .../

/I agree that/

/I agree about/on/upon/

$\boldsymbol{S}$ is the preposition with; $\boldsymbol{d a}$ indicates to which is followed by an infinitive verb form; che stands for the conjunction that and otnosno is equivalent to the English prepositions about/on/upon.

The overall number of saglasen sam utterances and their percentage rate is presented in the table:

\begin{tabular}{|l|c|c|}
\hline \multicolumn{1}{|c|}{ Bulgarian reference corpus } & $\begin{array}{c}\text { Number of utterances } \\
\text { commissive }\end{array}$ & $\begin{array}{c}\text { Percent } \\
\text { commissive }\end{array}$ \\
\hline P1 saglasen sam + s-CL & 1 & $4.35 \%$ \\
\hline P2 saglasen sam $+d a-I N F$ & 5 & $21.74 \%$ \\
\hline P3 saglasen sam $+s-C L+d a-I N F$ & 15 & $65.22 \%$ \\
\hline P4 saglasen sam + che $+C L$ & 1 & $4.35 \%$ \\
\hline P5 saglasen sam + otnosno-CL & 1 & $4.35 \%$ \\
\hline Total & $\mathbf{2 3}$ & $\sim \mathbf{1 0 0 \%}$ \\
\hline
\end{tabular}

The leading position takes P3 syntactic pattern. In 15 out of 23 cases saglasen appears in $\mathrm{P} 3$ valency pattern which adds a prepositional complement clause 
denoting either an action, an entity or a person followed by an infinitive form. Structures of that type were not identified in the British corpus. The database shows that in 11 cases the social status and distance between the participants in the communicative situation are not equal, which asks for a high level of formality. The latter is expressed by additional illocutionary acts highlighting the commissive illocutionary force. Obviously, in situations where there are indications of hierarchical footing extra speech acts are needed to guarantee the sincerity condition of the utterance of agreement. For example:

Saglasen sam s reshenieto na komisiyata da vlyazat $v$ sila novite zakonovi naredbi.

/in En: I agree with the committee's decision to enforce the new legislation./

With regard to the other syntactic patterns, P1 and P5 become explicit in one case each in which the sincerity condition is not as strong as in P3 syntactic structure, since the commissive aspect is not guaranteed either by a promise or a guarantee or other commissive acts.

Pattern 2 saglasen sam + da-INF occurs in 5 utterances and is similar in pragmatic use to the same syntactic pattern in the British corpus. Interestingly, in 4 out of 5 cases the communicative act is preceded or followed by an expressive illocutionary act, for example an act of approval which on its part expresses support for a state of affairs or activity that is worth being done and that the action is intentional and aims to be beneficial not only to the hearer but to the other party as well. In contrast, no expressive utterances were found in the British corpus. Since expressive communicative acts focus mainly on the mental states of the interlocutors, they illustrate a psychological mode which may be connected to a certain feeling, such as joy, excitement or sympathy, which undoubtedly indicates that a more personal attitude is added to the commissive act of agreement. This can be viewed as an emotional attitude to the whole speech situation in which the speaker may seem personally involved in the matter agreeing not only with the statement that the other party is saying but believing him/her as well. Again, positive politeness is expressed though illustrated in a different way.

The last pattern in the discussion is $\mathrm{P} 4$ saglasen sam $+\boldsymbol{c h e}+\boldsymbol{C L}$ in which che is used as a conjunction identical to that in English language and pragmatically does not show any marked deviations from its English equivalent, though extra illocutionary acts are added to differentiate the assertive from the commissive use. 


\section{Results/ Key Findings}

Based on findings and observations, the overall analysis indicates that all performatives used in the structure of agree speech acts refer to the sincerity condition in the communicative act and serve a social function, that is, by agreeing to commit themselves to tolerating an action the speaker is doing what is socially acceptable and expected which could present him/herself as an educated member of society.

In general, it seems that the majority of agree commissive utterances in both corpora take the form of bare performatives which implicate politeness in themselves. They could be considered beneficial to the hearer as the speaker assumes an obligation to accept and commit further actions to the proposition made by the hearer beforehand.

In both corpora the speaker tries to preserve the other party's positive selfimage and act to his/her best interest. The results illustrate that:

- the emotional contour in native speakers is not that distinct as it is in Bulgarian examples considering that the bare performatives are enough to illustrate politeness;

- on the other hand, Bulgarian learners of English tend to shorten the social distance and emphasize on the emotional aspect of the speech act by expressing sympathy and personal attitude to the speech situation.

- the preferred choice of agree patterns with combinations of other speech acts shows that Bulgarian leaners are more likely to emphasize on solidarity and closeness and diminish the level of formality.

\section{Conclusion and Implications}

The contributions of the paper can be seen in the fact that:

- Valency patternbank model can contribute to the identification and analysis of the syntactic structures as the linguistic competence will enhance development of communicative competence;

- in pedagogy teachers should help learners acquire not only linguistic knowledge of the way the speech act is realized but also dwell on the social variables that influence the successful performance of the act.

- teachers should enable learners to perform successful speech acts in order to avoid cross-cultural miscomprehension;

- besides linguistically correct agree formulas learners need to be made aware of the significance of social power, social distance and imposition in communication so that the communicative act be taken as genuine. 


\section{References:}

Austin 1962: Austin J.L. How to Do Things with Words. Oxford: Oxford University Press.

Bach 2004: Bach K. Pragmatics and the Philosophy of Language. - In: Horn L. R., G. Ward (eds.). The Handbook of Pragmatics. Oxford: Basil Balckwell. 463-487.

Biber, Conrad, Reppen 1998: Biber D., Conrad S., R. Reppen. Corpus Linguistics. Investigating Language Structure and Use. Cambridge: CUP.

Dimitrova 2009: Dimitrova S. Lingvistichna pragmatika. IK Veles. Sofia. 61-68.

Downing, Locke 2006: Downing A., P. Locke. English Grammar: A University Course. $2^{\text {nd }}$ ed. Abingdon and New York: Routledge.

Herbst et al 2004: Herbst T., Heath D., Roe I. F., D. Gotz (eds.). A Valency Dictionary of English: A Corpus-Based Analysis of the Complementation Patterns of English Verbs, Nouns and Adjectives. Berlin: Mouton de Gruyter.

Herbst, Schüller 2008: Herbst T., S. Schüller. Introduction to Syntactic Analysis. Tübingen: Narr.

Hristov 2008: Hristov B. Politeness in Requests in English and Bulgarian. MA Student Thesis. University of Oxford.

Hymes 1972: Hymes D. On Communicative Competence. - In: Pride J. B., J. Homles (eds.). Sociolinguistics. Harmondswortth: Penguin. 269-293.

Ivanova 2012: Ivanova I. Enhancing Students' Pragmatic Awareness: Explicit Versus Implicit Instruction in Textbooks. - Episkop-Konstatinovi cheteniya. Vol. 18. Shumen: Shumen University Publishing Press. 157-163.

Peneva 2015. Peneva D. The Speech Act of Apology in Bulgarian Learners of English. Unpublished doctoral thesis. Konstantin Preslavsky University of Shumen, 2015.

Searle 1969: Searle J. An Essay in the Philosophy of Language. Cambridge: Cambridge University Press.

Strawson 1964: Strawson P. Intention and Convention in Speech Acts. - The Philosophical Review. 73, 439-460.

Thomas 1986: Thomas J. The Dynamics of Discourse: A Pragmatic Analysis of Confrontational Interaction. Unpublished PhD Thesis, Lancaster University.

Tsvetkova 2014: Tsvetkova M. The Problem of Equivalence in Contrastive Analysis. In: Nedelcheva S., Cheshmedzhieva-Stoycheva D., D. Mossop (eds.). English Studies: Translation and Linguistics. Shumen: Shumen University Press, 132-136.

Vlahova 2000: Vlahova R. Monofonichna i polifonichna rech. Lingvistika, semiotika, filologiya. Sema RSH Publishing.

Yule 1996: Yule G. Pragmatics. Oxford University Press. 